\title{
Leading a Patient of Ankylosing Spondylitis to Death by latrogenic Spinal Fracture
}

\author{
Jae-Sang Oh, Jae-Won Doh, Jai-Joon Shim, Kyeong-Seok Lee \\ Department of Neurosurgery, Soonchunhyang University Cheonan Hospital, Cheonan, Korea
}

\begin{abstract}
Fractures in ankylosing spondylitis (AS) are often difficult to identify and treat. If combined with osteoporosis, the spine becomes weaker and vulnerable to minor trauma. An 83-year-old woman with a history of chronic AS and severe osteoporosis developed paraparesis and voiding difficulty for 4 days prior. She had been placed in the lateral decubitus position in a bedridden state in a convalescent hospital due to the progressive paraparesis. The laboratory findings showed $\mathrm{CO}_{2}$ retention in the arterial blood gas analysis. After the patient was transferred to the computed tomography (CT) room, a CT was taken in the supine position. Approximately half an hour later, the resident in our neurosurgical department checked on her, and the neurological examination showed a complete paraplegic state. She was treated conservatively and finally expired 20 days later.
\end{abstract}

Key Words: Ankylosing spondylitis · Osteoporosis $\cdot$ Spine fractures

\section{INTRODUCTION}

Fractures in ankylosing spondylitis (AS) are often difficult to identify and treat. If combined with osteoporosis, the spine becomes weaker and vulnerable to minor trauma ${ }^{2)}$. Before coming up with a definitive management, up to $15 \%$ of patients experience secondary deterioration of neurologic status ${ }^{5)}$. We describe here a case of a T8 fracture in an elderly AS patient associated with osteoporotic kyphosis, leading to paraplegia due to further aggravated fracture-dislocation and death during the nursing care at convalescent hospital.

\section{CASE REPORT}

An 83-year-old woman with a history of chronic AS and severe osteoporosis developed paraparesis and voiding difficulty 4 days prior. She had been placed in the lateral decubitus position in a bedridden state in a convalescent hospital due to the progressive paraparesis. She had a severe kyphosis of the thoracolumbar junction. One week before, she had a trivial injury, a snap while she was being lifted up in her bed. After this minor trauma, she developed paraparesis (grades 2-3) 3

- Received: October 9, 2015 • Revised: January 27, 2016

- Accepted: February 29, 2016

Corresponding Author: Jae-Won Doh

Department of Neurosurgery, Soonchunhyang University Cheonan

Hospital, 31 Suncheonhyang 6-gil, Dongnam-gu, Cheonan 31151, Korea

Tel: +82-41-570-2180, Fax: +82-41-572-9297

E-mail: metatron1324@hotmail.com

$\otimes$ This is an open access article distributed under the terms of the Creative Commons Attribution Non-Commercial License (http://creativecommons.org/licenses/by-nc/4.0/) which permits unrestricted non-commercial use, distribution, and reproduction in any medium, provided the original work is properly cited. days later, so she was transferred to Soonchunhyang University Cheonan Hospital.

Plain radiographs of the thoracolumbar junction showed a hyperextension fracture at T9-10 with ossification of the anterior longitudinal ligament, calcification of the intervertebral discs and complete vertebral fusion (bamboo spine) (Fig. 1). Plain radiographs ware checked on supine position, but her preexisting curvature was not changed at that time. Because folded blankets ware supported on her neck and hip area while nurse held her position. The radiographs also showed severe
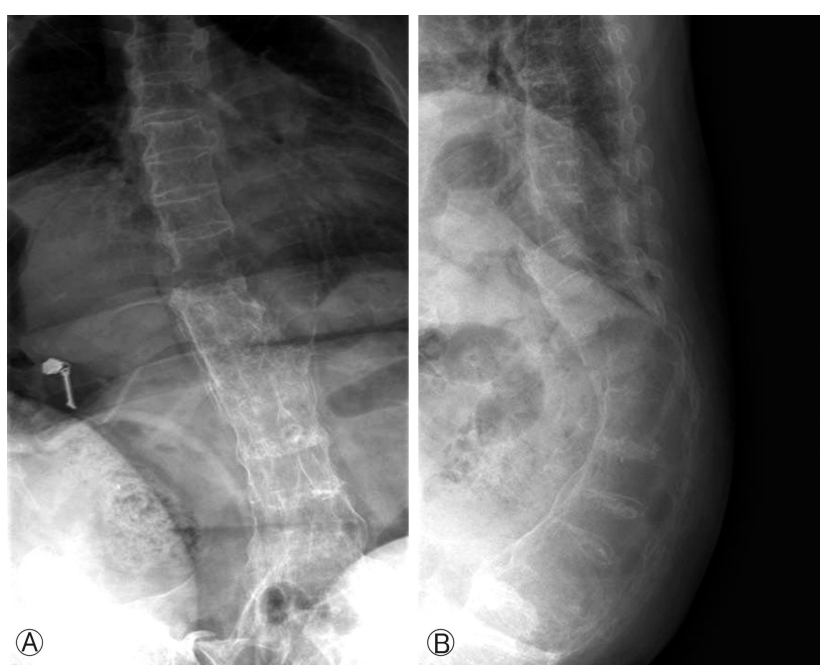

Fig. 1. Anteroposterior (A) and lateral (B) images of thoracolumbar junction obtained from Emergency Department. The images show a hyperextension fracture-dislocation at T9-10 with ossification of the anterior longitudinal ligament, calcification of the intervertebral discs, and complete vertebral fusion (bamboo spine). 


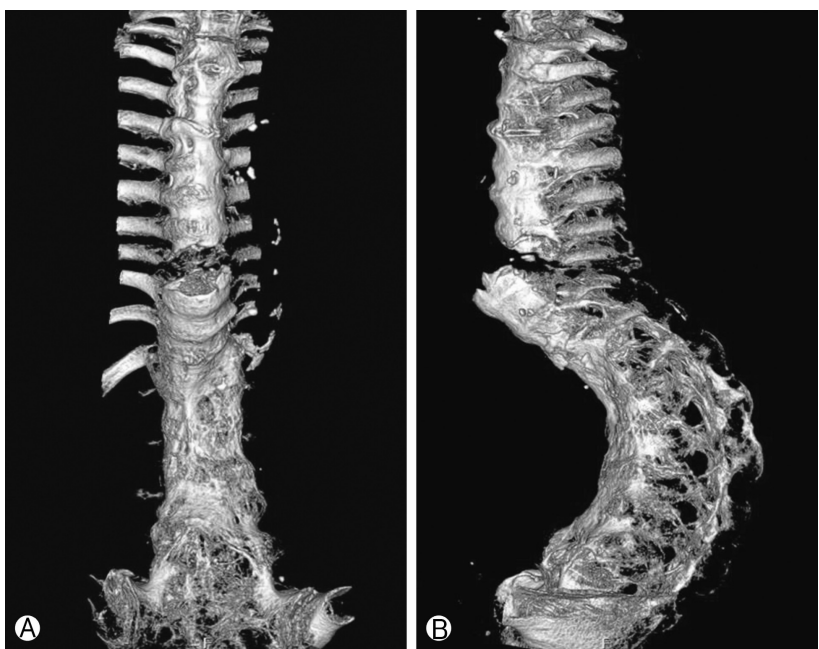

Fig. 2. Anteroposterior (A) and lateral (B) 3-dimensional computed tomography images of the thoracolumbar junction showing the more aggravated spinal fracture-dislocation.

osteoporotic change (bone mineral density, -4.8). The laboratory findings showed $\mathrm{CO}_{2}$ retention in the arterial blood gas analysis, and she already had a history of asthma. Her creatinine level was elevated $(1.9 \mathrm{mg} / \mathrm{dL})$, which implied acute renal failure. In the Emergency Department, the emergency physician ordered thoracolumbar 3-dimensional computed tomography (3DCT) (Fig. 2). After the patient was transferred to the CT room, a CT was taken in the supine position without any assistant. Approximately half an hour later, the resident in our neurosurgical department checked on her, and the neurological examination showed a complete paraplegic state. The spine fracture was more aggravated on 3DCT. Magnetic resonance imaging (MRI) could not check for preventing aggravation of curvature and cord injury. She was treated with restrictive immobilization on lateral decubitus because she had severe respiratory problems and her family wanted no further treatment. She was treated conservatively and finally expired 20 days later.

\section{DISCUSSION}

AS is seronegative arthropathy that affects the sacroiliac joints and spine. Nearly all AS patients test positive for the $H L A-B 27$ gene. The prevalence is $1-3$ in 1,000 , and men are more often affected than women at a ratio of $2: 1^{3,4,14)}$. In the vertebral body, ascending inflammation with apophysis and enthesis leads to primarily bony erosion and then bone formation in the form of enthesophytes and syndesmophytes. Calcification of the longitudinal ligaments restricts the normal spinal movement, resulting in the bamboo spine appearance. The rigid spine functions as a long bone and is the major factor in spinal fracture patients who are predisposed to $\mathrm{AS}^{7}$.

Spinal fracture is more common in AS patients than in general population, with incidence ranging from $5 \%$ to $15 \%{ }^{10,15}$. Because they also have a high incidence of neurologic compli- cations as an symptom, up to $15 \%$ of patients have secondary deterioration in their neurologic status ${ }^{1}$. In addition, the mortality risk is significantly increased in AS following traumatic spinal fracture, with the range of $18 \%-32 \%$ in the acute phase. Patients with AS often have medical comorbidities, including aortic insufficiency, cardiac conduction abnormalities, uveitis and pulmonary diseases. The inflammation process leads to ankylosis of the spine motion segments at costovertebral joints, and makes patients prone to developing pulmonary fibrosis later ${ }^{14)}$. Our patient already had asthma, and the cause of death was pulmonary complications from her bedridden state.

The management with surgery is determined by the both of fracture pattern and patient's overall medical status. Treatments range from external orthosis, traction, halo vest placement, to surgical management. Stable fractures are amenable to conservative treatment, such as mobilization in a cervical collar or a clamshell thoracolumbosacral orthosis ${ }^{5,715)}$. Definitive surgical indications include deteriorating neurological status, irreducible deformity and presence of an epidural hematoma or another source of spinal cord compression ${ }^{8,14,15)}$. Surgical management in AS has an increased rate of neurological recovery compared to nonsurgical treatment, and the mortality rate in nonoperative patients is higher than that in operative groups of age more than $70(51 \% \text { vs. } 23 \%)^{13)}$. Anteriorposterior $\left(360^{\circ}\right)$ procedures increase surgical time, morbidity and mortality. Often, patients can be managed by single posterior approach or staged procedures with minimally invasive fixation using percutaneous screw".

AS is a challenging diagnostic problem. Plain radiographs usually do not easily demonstrate the changes in the outline of the bone, and assessment is more difficult because the overlying structures of the cervicothoracic junction overshadow the osteopenic spine.

The most efficient diagnostic tool is MRI followed by CT. However, as in our case, in severe thoracolumbar kyphosis, it may be difficult to place the patient to supine position without causing a secondary neurological injury. Some articles reported that it may help to raise the pelvis ${ }^{12)}$. Severe osteoporosis or osteopenia is a high risk, so in all image evaluation rooms and operating rooms, patients should be positioned very carefully. Although most spinal cord injury in patients with AS was occurred from falls, this patient had severe thoracolumar spinal fracture despite minor trauma. As well as vulnerability of AS, severe osteoporosis with kyphotic curvature made such catastrophic result (death) ${ }^{7}$. In AS, there was no report that fatal trauma was occurred in positioning for CT evaluation, although some cases which had fatality from minor trauma were resported ${ }^{6}$. There are a report about exacerbating cervical spine injury by applying a hard collar accompanied with angulation of cervical spine ${ }^{11)}$. In our case, she also had severe thoracolumbar kyphotic angulation. AS, kyphotic angle, and severe osteoporosis led to death.

South Korea is gradually becoming an aging society, and the birth rate has been falling year by year. Recently, the number of convalescent hospitals has increased radically. The pa- 
tients in these hospitals tend to have difficulties in communicating with others. And when they are transferred to more specialized hospitals, it is frequently the case that their medical histories are incomplete, lacking the information from which one can make critical decisions on the patients' behalf. For these reasons, patients in convalescent hospitals are easily exposed to medical accidents. We believed that all such conditions contributed in our case. Therefore, to solve these problems, it is important to share medical records, and we need to pay more attention to patients with AS.

\section{CONCLUSION}

AS patients are at higher risk of spinal fracture, especially in case of elderly patients with osteoporosis and kyphotic curvature. Because AS is a challenging diagnostic problem, MRI and CT are imperative diagnostic tools. Emergency physicians and neurosurgeons must consider iatrogenic fractures and secondary neurological injuries in AS with severe osteorosis when taking images, positioning patients in the operating room or performing reduction maneuvers.

\section{CONFUCT OF INTEREST}

No potential conflict of interest relevant to this article was reported.

\section{REFERENCES}

1. Anwar F, Al-Khayer A, Joseph G, Fraser MH, Jigajinni MV, Allan DB: Delayed presentation and diagnosis of cervical spine injuries in long-standing ankylosing spondylitis. Eur Spine J 20: 403-407, 2011

2. Bessant R, Keat A: How should clinicians manage osteoporosis in ankylosing spondylitis? J Rheumatol 29:1511-1519, 2002

3. Braun J, Sieper J: Ankylosing spondylitis. Lancet 21;369:13791390, 2007
4. Brown MA: Progress in spondylarthritis. Progress in studies of the genetics of ankylosing spondylitis. Arthritis Res Ther 11:254, 2009

5. Caron T, Bransford R, Nguyen Q, Agel J, Chapman J, Bellabarba C: Spine fractures in patients with ankylosing spinal disorders. Spine (Phila Pa 1976) 35:E458-464, 2010

6. Etgen T, Rieder G: Fatality from minor cervical trauma in ankylosing spondylitis. BMJ Case Rep 2009. pii: bcr12.2008.1400, 2009

7. Hitchon PW, From AM, Brenton MD, Glaser JA, Torner JC: Fractures of thethoracolumbar spine complicating ankylosing spondylitis. J Neurosurg 97(2 Suppl):218-222, 2002

8. Kanter AS, Wang MY, Mummaneni PV: A treatment algorithm for the management of cervical spine fractures and deformity in patients with ankylosing spondylitis. Neurosurg Focus 24: E11, 2008

9. Lee JK, Park KS, Park MS, Kim SM, Chung SY, Lee do S: Surgical treatment of lumbar hyperextension injury in ankylosing spondylitis. Korean J Spine 10:195-199, 2013

10. Mundwiler ML, Siddique K, Dym JM, Perri B, Johnson JP, Weisman MH: Complications of the spine in ankylosing spondylitis with a focus on deformity correction. Neurosurg Focus 24:E6, 2008

11. Papadopoulos MC, Chakraborty A, Waldron G, Bell BA: Lesson of the week: exacerbating cervical spine injury by applying a hard collar. BMJ 319:171-172, 1999

12. Rinsky LA, Reynolds GG, Jameson RM, Hamilton RD: A cervical spinal cord injury following chiropractic manipulation. Paraplegia 13:223-227, 1976

13. Rowed DW: Management of cervical spinal cord injury in ankylosing spondylitis: the intervertebral disc as a cause of cord compression. J Neurosurg 77:241-246, 1992

14. Sapkas G, Kateros K, Papadakis SA, Galanakos S, Brilakis E, Machairas G, et al: Surgical outcome after spinal fractures in patients with ankylosing spondylitis. BMC Musculoskelet Disord 10:96, 2009

15. Westerveld LA, Verlaan JJ, Oner FC: Spinal fractures in patients with ankylosing spinal disorders: a systematic review of the literature on treatment, neurological status and complications. Eur Spine J 18:145-156, 2009 